\title{
Balloon Dilatation of Laryngotracheal Stenosis: Hospital Ampang Experience
}

\author{
LY Loo ${ }^{\mathrm{a}, \mathrm{b}}$, Mawaddah $\mathrm{A}^{\mathrm{a}}$, Shahrul $\mathrm{H}^{\mathrm{b}}$, Khairullah $\mathrm{A}^{\mathrm{c}}$, \\ a Jabatan ORL-HNS Pusat Perubatan Universiti Kebangsaan Malaysia, \\ b Jabatan ORL-HNS Hospital Ampang, Selangor, \\ c Jabatan ORL-HNS Universiti Sains Islam Malaysia.
}

\begin{abstract}
The upper airway is a crucial structure. It becomes a grave problem should it be narrowed. Several methods of treatment were rendered for patients with laryngotracheal stenosis. We share our experience with the combination total intravenous anaesthesia and apneic pause technique with or without steroid injection. Four cases of laryngotracheal stenosis were observed in Hospital Ampang: two adult and two paediatric cases. Age, gender, causative factor, stenosis segment length, grade or severity were observed before and after dilatation, number of dilatation were observed and compared. The outcome measures are decannulation and avoidance of tracheostomy. All cases had improvement of symptoms. Half or $50 \%$ of the patient required repeated balloon dilatations. The paediatric cases successfully avoided tracheostomy while the adult cases successfully decannulated with no complication from the procedure. Balloon dilatation by total intravenous anaesthesia coupled with apneic method is a safe and effective method of treatment for the narrowed airway.
\end{abstract}

KEY WORDS: Balloon dilatation, Stenosis, Larynx, Trachea

\section{INTRODUCTION}

Narrowing of the larynx can occur in the supraglottic, glottic or subglottic region. The commonest region involved being subglottic region, may be either congenital or acquired with the latter being a complication of prolonged endotracheal intubation. In adults, posterior glottic and subglottic stenoses are the most common complications of prolonged endotracheal intubation. Other causes included external laryngeal trauma, iatrogenic trauma following laser, microcautery, cryosurgery or electrosurgical treatment.

The management of subglottic stenosis is mainly divided into open and endoscopic. In the era of minimally invasive surgery, endoscopic balloon and bougie dilatation is initially attempted for laryngotracheal stenosis. Recent studies favour endoscopic dilatation in selected patients. The combination of total intravenous anaesthesia (TIVA) with the depth of anaesthesia monitoring in this endoscopic procedure compliments centers where jet ventilation is unavailable while eliminating delibitating complications for example, pneumothorax.

Corresponding author:

Dr. Loo Lit Yee (LY Loo)

Department of Otorhinolaryngology Head and Neck Surgery,

Universiti Kebangsaan Malaysia Medical Centre Jalan Yaacob Latiff, Bandar Tun Razak,

56000, Cheras, Kuala Lumpur

Tel No: +60122336622 Fax: +60391456675

E-Mail : lityee@gmail.com

\section{MATERIALS \& METHODS}

In the year 2014, four cases of laryngotracheal stenosis were observed. Two cases involving adult and the other two cases involving paediatric patients. All four cases had undergone balloon dilation by total intravenous anaesthesia with apneic pause technique with or without steroid injection.

Case 1:

A 1 year 2 months old girl was diagnosed with grade II Cotton-Myer subglottic stenosis (Fig.1) and gastroesophageal reflux disease (GERD). She was born prematurely with multiple hospital admission for airway related issues and was finally referred to ORL-HNS clinic. Balloon dilatation was done (Fig.2) and the immediate result after dilatation (Fig.3).

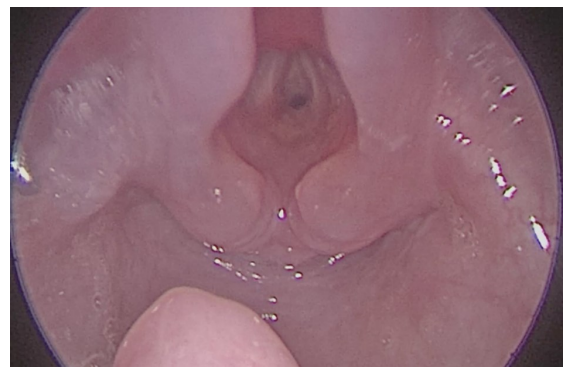

Figure 1: Case 1 Endoscopic view of the Subglottic stenosis

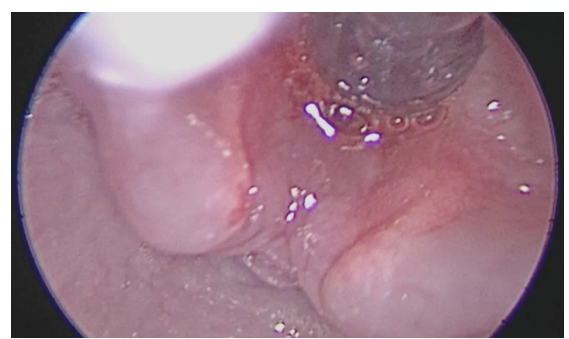

Figure 2: Case 1 Balloon dilatation 


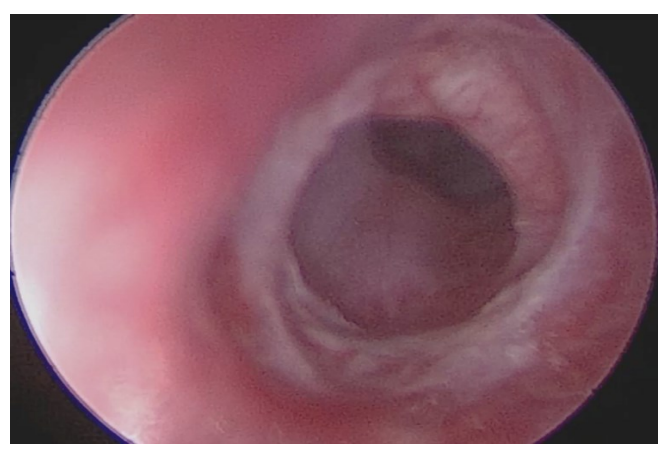

Figure 3: Case 1 Immediate result adequate airway immediately

\section{Case 2:}

A 18 year-old female diagnosed with tracheal stenosis secondary to severe inhalational burn injury. Tracheostomy was done for prolonged ventilation. Her worsening of breathing prompted a CT imaging. It revealed normal glottis and subglottic caliber. Trachea narrowing segment $2.1 \mathrm{~cm}$ below the tip of endotracheal tube, $14 \mathrm{~mm}$ in length and narrowest at $7 \mathrm{~mm}$ width. She was referred to Otorhinolaryngology department for evaluation.

\section{Case 3:}

A 3 month-old girl was diagnosed with subglottic stenosis grade III Cotton-Myer. She has underlying Down syndrome with repaired large ventricular septal defect (VSD) and ligated patent ductus arteriosus (PDA). She was intubated for 3 days following birth. She was referred to Otorhinolaryngology clinic for biphasic stridor with poor weight gain. She was electively admitted for microlaryngobronchoscopy and intervention. She was booked for post-operative Paediatrics ICU monitoring in view of high risk of difficult ventilation intraoperatively.

Discussion with the attending anaesthetist was done prior to the procedure. Because the patient was not in respiratory distress and the bedside flexible laryngoscopy did not reveal significant supraglottic pathology, decision was made to proceed with spontaneous respiration technique. Intraoperatively, the patient was sedated with intravenous infusion of propofol and remifentanil. No muscle relaxant were given. Adequate oxygenation and ventilation was maintained throughout the procedure using insufflation and intermittent manual bagging. Intraoperative findings revealed membranous subglottic stenosis Cotton-Myer grade III.

During the early post-operative monitoring in PICU, she did not require intubation needing only a facemask to maintain oxygenation. She was discharge well after one-day post operatively to the general paediatrics ward.
Case 4:

A 17 year-old male with polytrauma due to motor vehicle accident had been tracheostomised for prolonged ventilation. Multiple attempts to wean off oxygen supplement failed and the he was referred to Otorhinolaryngology clinic. Whilst CT scan did not reveal any obvious tracheal stenosis, flexible nasopharyngolaryngoscopy revealed Cotton-Myer grade III tracheal stenosis $3.3 \mathrm{~cm}$ from glottis with fibrous bands in left and right tracheal wall.

In all 4 cases discussed here, apneic pauses technique was utilized. The patients were given TIVA with remifentanil and propofol. Analgesia/ sedation was achieved by infusion of remifentanil ( 0.20 to $0.25 \mathrm{microg} / \mathrm{kg} / \mathrm{min})$ and propofol in titrated doses. The depth of the anaesthesia is monitored with Bispectral Index (BIS) at 45 to 55 throughout the procedure.

The patient would be hyperventilated for 1 minute. Insufflation technique for the delivery of oxygen via a ventilation port on the side of the direct laryngoscope was used throughout the procedure except during the inflation of the balloon. Oxygen saturation is observed and intermittent bagging would be commenced should the oxygen saturation dips below 95\%. Insufflation of oxygen was made continuously via the tracheostomy tube, the tube was then removed during the balloon inflation rendering apneic pauses and then the tracheostomy was reinserted. This step is repeated until dilatation was completed.

Upon adequate general anaesthesia is achieved, the stenotic segment is excised radially by cold instrumentation size 11 blade and the balloon is carefully guided into the level of stenotic segment and dilated with the appropriate pressure for 50 seconds. After each dilatation, the patient is again hyperventilated for 1 minute. Continuous observation of oxygen saturation levels and electrocardiogram are mandatory. This dilatation is repeated for a total of 3 times. Steroid (triamcinolone) injection was given only to the adult cases. It was injected via a butterfly needle with its wings clipped off on one side and the other side clipped leaving a small area to allow it to be held with a Blakesley grasper (Fig.4). It is then guided to the lesion and injected via a syringe. Hemostasis secured using adrenaline soaked gauze.

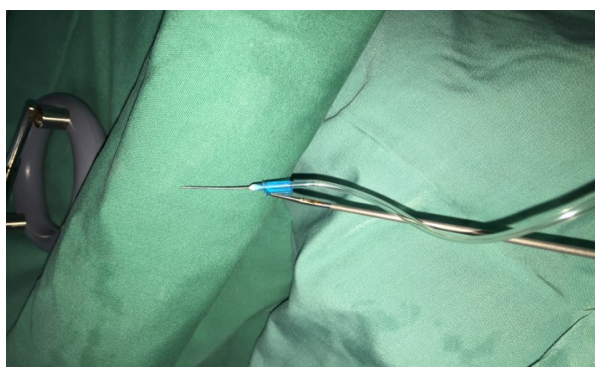

Figure 4: Injection via a butterfly needle and syringe held by a Blakesley grasper. 
Table 1: Findings from the 4 cases.

\begin{tabular}{|c|c|c|c|c|}
\hline & Case 1 & Case 2 & Case 3 & Case 4 \\
\hline Age & 1 year 2 months & 18 years & 3 months & 17 years \\
\hline Gender & Female & Female & Female & Male \\
\hline $\begin{array}{l}\text { Causative } \\
\text { Factor }\end{array}$ & $\begin{array}{l}\text { Premature, GERD, } \\
\text { Intubation for } \\
\text { 5days }\end{array}$ & $\begin{array}{l}\text { Severe burn, } \\
\text { tracheostomy for } \\
\text { prolonged } \\
\text { ventilation }\end{array}$ & $\begin{array}{l}\text { Intubated for } 3 \\
\text { days }\end{array}$ & $\begin{array}{l}\text { Tracheostomy for } \\
\text { prolonged } \\
\text { ventilation }\end{array}$ \\
\hline $\begin{array}{l}\text { Stenosis } \\
\text { segment length }\end{array}$ & $2 \mathrm{~mm}$ & $\begin{array}{l}4 \mathrm{~mm} \text { (proximal) } \\
2 \mathrm{~mm} \text { (distal) }\end{array}$ & $2 \mathrm{~mm}$ & $5 \mathrm{~mm}$ \\
\hline $\begin{array}{l}\text { Segment } \\
\text { characteristics }\end{array}$ & Membranous & $\begin{array}{l}\text { Both proximal and } \\
\text { distal; } \\
\text { membranous } \\
\text { Distal segment on } \\
\text { second dilatation; } \\
\text { matured scar, } \\
\text { crescentic shaped }\end{array}$ & Membranous & Membranous \\
\hline Balloon size & $5 \times 24 \mathrm{~mm}$ & $14 \times 40 \mathrm{~mm}$ & $5 \times 24 \mathrm{~mm}$ & $14 \times 40 \mathrm{~mm}$ \\
\hline Pressure & $14 \mathrm{~atm}$ & $10 \mathrm{~atm}$ & $14 \mathrm{~atm}$ & $10 \mathrm{~atm}$ \\
\hline $\begin{array}{l}\text { Before } \\
\text { Dilatation }\end{array}$ & $\begin{array}{l}\text { Grade II } \\
\text { Cotton-Myer }\end{array}$ & $\begin{array}{l}\text { Tracheal stenosis; } \\
2 \text { stenosis } \\
\text { segments; } 3.5 \mathrm{~mm} \\
\text { \&5.5 mm below } \\
\text { vocal cord; } \\
50 \% \text { stenosis } \\
\text { Grade II } \\
\text { Cotton-Myer }\end{array}$ & $\begin{array}{l}\text { Grade III } \\
\text { Cotton-Myer }\end{array}$ & $\begin{array}{l}\text { Near occlusion of } \\
\text { tracheal stenosis; } \\
\text { suprastoma. } \\
\text { Grade III } \\
\text { Cotton-Myer }\end{array}$ \\
\hline After Dilatation & $\begin{array}{l}\text { Grade I Cotton- } \\
\text { Myer } \\
\text { Matured spiral scar }\end{array}$ & $\begin{array}{l}\text { Proximal segment } \\
15 \% \text { stenosis, } \\
\text { matured scar at } \\
\text { distal segment, } \\
\text { decannulated. }\end{array}$ & $\begin{array}{l}\text { Grade I } \\
\text { Cotton-Myer } \\
\text { Matured } \\
\text { crescentic scar }\end{array}$ & $\begin{array}{l}\text { Minimal matured } \\
\text { scar tissue seen, } \\
\text { decannulated. }\end{array}$ \\
\hline $\begin{array}{l}\text { Number of } \\
\text { dilation(s) }\end{array}$ & 2 & 2 & 1 & 1 \\
\hline
\end{tabular}

\section{RESULTS}

The procedure was repeated in cases 1 and 2 with an interval of 3 weeks between procedure. Six months after the final procedure, all 4 cases had successful results in terms of improvement of symptoms namely no stridor, no breathlessness, and reduction of stenosis size. $50 \%$ of the patient required repeated balloon dilatations. Repeated balloon dilatation is indicated for Case 1 in view of failure to thrive and also respiratory distress where the patient was stridorous with subcostal recession. Case 2 required a second dilatation because the patient was not able to wean off her tracheostomy and also stridorous on exertion. It is also necessary to mention that the repeat balloon dilatation for this case was done to the proximal stenosis segment only with none necessary for the distal segment. The paediatric group patients successfully avoided tracheostomy while the adult group of patients successfully had the tracheostomy decannulated. None suffered any complication pertaining to the procedure.

\section{DISCUSSION}

Balloon dilatation (BD) technique as a treatment for laryngotracheal stenosis has developed from strength to strength after its introduction in 1984 (1). Its success rates are comparable to open technique (2-4). Morbidity and improvement in quality of life favoured BD (3). Others agreed that $\mathrm{BD}$ is the primary option and reserve open technique in case of the failure of BD.

BD with or without adjuvant procedure was reported to be a successful option for treatment of laryngotracheal stenosis of various aetiologies. 
Stenosis due to congenital laryngeal stenosis (4), recurrent respiratory papilomatosis (5), post intubation tracheal stenosis (6), idiopathic subglottic stenosis (7) are among others studied and produced remarkable successes. However, a negative prognostic factor in patients was identified being concomitant airway disorders for example laryngotracheomalacia, suglottic cyst, subglottis granulation and suprastomal granulation. Failed balloon dilatations in children with concomitant airway disorders were as high as $75 \%$ where success rate is at $37.5 \%(P=0.048)(8)$

In this case series, it is worthwhile to mention that it had been successfully demonstrated that BD could be a single modality treatment for laryngotracheal stenosis. The results achieved can be a precursor for larger studies to be conducted to strengthen the reason for its application in laryngotracheal stenosis or be considered as the first line treatment before any other more invasive procedures such as $\mathrm{CO}_{2}$ laser resection and open laryngotracheoplasty are considered.

Traditionally, cases as such required jet ventilation to support the oxygen saturation of the patient to provide ample oxygenation for normal cellular activity. Unfortunately, it is not readily available in every hospital setting. In all 4 cases discussed here, apneic pauses technique was utilized even on the patients with tracheostomy tubes. The patients were given TIVA with remifentanil and propofol. Analgesia/sedation was achieved by infusion of remifentanil (0.20 to $0.25 \mathrm{microg} / \mathrm{kg} / \mathrm{min})$ and propofol in titrated doses. Oxygen was delivered by insufflation technique via a ventilation port on the side of the direct laryngoscope throughout the procedure except during the inflation of the balloon in case 1 and case 3 . In case 2 and 4 insufflation was delivered via the tracheostomy and the tracheostomy tube removed during balloon dilatation. Hence, all cases observed apneic pauses.

With TIVA, propofol itself exerts the antiemetic property that reduces postoperative nausea \& vomiting in comparison with inhalational anaesthesia. Propofol also reduces airway reaction, minimizing any untoward complication such as bronchospasm and laryngospasm both during anaesthesia and post-operative recovery period but on the contrary inducing bronchodilation. These properties are especially welcomed when the operation involved handling and manipulation of the airway.(9)

The depth of the anaesthesia is monitored with Bispectral Index (BIS). At values between 70 and 80, loss of consciousness occurs. The values that reflect adequate general anesthesia effect are from 40 to 60. BIS indices less than 30 represent deep anesthesia. Hence, the anesthesiologist adjust accordingly to increase this value by adjusting the dosage of anaesthetic agents. (10)

\section{CONCLUSIONS}

Balloon dilatation by total intravenous anaesthesia coupled with apneic method is a safe and effective method of treatment for the narrowed airway. Promising results have been observed and showed that it allowed downsizing of the stenosis while avoiding other more invasive surgical intervention and its associated complication.

Conflict of interest:

The authors declare that there is no conflict of interest regarding the publication of this paper.

\section{REFERENCES}

1. Cohen M, Weber T, Rao C. Balloon dilatation of tracheal and bronchial stenosis. American journal of roentgenology. 1984;142(3):477-8.

2. Maresh A, Preciado DA, O'Connell AP, Zalzal $\mathrm{GH}$. A Comparative Analysis of Open Surgery vs Endoscopic Balloon Dilation for Pediatric Subglottic Stenosis. JAMA Otolaryngology-Head \& Neck Surgery. 2014;140(10):901-5.

3. Sinacori JT, Taliercio SJ, Duong E, Benson C. Modalities of treatment for laryngotracheal stenosis: the EVMS experience. The Laryngoscope. 2013;123(12):3131-6.

4. Blanchard $M$, Leboulanger $N$, Thierry $B$, Blancal JP, Glynn F, Denoyelle F, et al. Management specificities of congenital laryngeal stenosis. The Laryngoscope. 2014;124(4):1013-8.

5. Siegel B, Smith LP. Management of complex glottic stenosis in children with recurrent respiratory papillomatosis. International journal of pediatric otorhinolaryngology.

2013;77(10):1729-33.

6. Lee WH, Kim JH, Park J-H. Fluoroscopically guided balloon dilation for postintubation tracheal stenosis. Cardiovascular and interventional radiology. 2013;36(5):1350-4.

7. Nouraei S, Sandhu G. Outcome of a multimodality approach to the management of idiopathic subglottic stenosis. The Laryngoscope. 2013;123(10):2474-84.

8. Whigham AS, Howell R, Choi S, Peña M, Zalzal $G$, Preciado D. Outcomes of balloon dilation in pediatric subglottic stenosis. Annals of Otology, Rhinology \& Laryngology. 2012;121(7):442-8.

9. Lauder GR. Total intravenous anesthesia will supercede inhalational anesthesia in pediatric anesthetic practice. Pediatric Anesthesia. 2015;25(1):52-64.

10. Al-Kadi MI, Reaz MBI, Ali MAM. Evolution of electroencephalogram signal analysis techniques during anesthesia. Sensors. 2013;13(5):6605-35. 